\title{
Changes to bodily appearance: the aesthetics of deliberate intervention
}

Søren Holm University of Manchester, Manchester

\begin{abstract}
Aesthetic plastic surgery is a branch of medicine using surgical techniques to alter the appearance of patients. In this paper it is considered whether aesthetic plastic surgery should be viewed as an art form. The question is answered by trying to see how aesthetic plastic surgery fits a number of classical concepts in philosophical aesthetics, concepts such as "artist" and "work of art". Further to elucidate the status of aesthetic plastic surgery, it is compared with competitive bodybuilding, another technique for changing appearance.
\end{abstract}

(F Med Ethics: Medical Humanities 2000;26:43-48)

Keywords: Aesthetic plastic surgery; bodybuilding; philosophical aesthetics

"For Beauty includes three conditions, integrity or perfection, since those things which are impaired are by the very fact ugly; due proportion and harmony; and lastly, brightness, or clarity, whence things are called beautiful which have a bright colour."1

The everyday language of medicine is filled with terms with explicit aesthetic connotations. In our charts we note symmetry, equality, smoothness and a great number of other aesthetic features of the bodies of our patients. Similarly various kinds of aesthetic judgment form part of the input of ordinary clinical decision making. In many forms of elective surgery we routinely consider how scars can be minimised and hidden, and medical treatments that have appearance-changing side effects are used only sparingly. Thus medicine and the aesthetic are inextricably intertwined.

In the present paper it is, however, not this "ordinary" connection between medicine and aesthetics, medical judgment and aesthetic judgment, that I want to investigate.

It is the much more explicit use of aesthetic notions within the branch of surgery called aesthetic plastic surgery and the claim of this branch of surgery to be linked to aesthetics which will be at the centre of the present paper (aesthetic plastic surgery is also sometimes referred to as "cosmetic surgery" but practitioners of this branch of surgery prefer not to use the term cosmetic). ${ }^{2}$ To investigate the link between aesthetic plastic surgery and aesthetics I will contrast two seemingly very different ways of changing the human body to a desired state, the one being aesthetic plastic surgery the other being (competitive) bodybuilding. The tension between the pretensions of these two very different practices will be brought out by asking a number of questions central to the classic understanding of aesthetics, ${ }^{34}$ questions such as: "Who is the artist?"; "Who is the audience?"; "What does this 'work of art' consist in?", and "Is it really art?".

In the present paper the emphasis will be on aesthetic surgery, and bodybuilding will be used mainly for contrast; but I believe bodybuilding to be a fascinating subject for further studies of the ways we human beings try to influence the appearance of our bodies.

\section{Aesthetic surgery and bodybuilding - two worlds apart?}

It is obvious that there are large differences between aesthetic plastic surgery and bodybuilding, but it is perhaps worthwhile right at the start of the analysis to outline those differences that are usually seen as most salient.

Aesthetic surgery is a branch of medicine, performed by medically certified surgeons, who practise a sub-specialty of plastic surgery. The aesthetic surgeon treats patients in a health care setting, and patients seek his or her help partly because this help is explicitly a part of medicine and health care. This relation to medicine both validates and legitimates the practice to a certain extent. During recent years there have been sustained attempts to have aesthetic plastic surgery recognised internationally as a bona fide sub-specialty of plastic surgery with its own certification requirements. ${ }^{2}$

In contrast bodybuilding is a sport on the fringe of organised sport. More organised sports view bodybuilding with suspicion because of persistent rumours about the frequent use of anabolic steroids and other performance-enhancing drugs. 
The differences between bodybuilding and aesthetic surgery can even be seen in the ways they are marketed. Whereas "journals" about bodybuilding are rather gaudy affairs sold on newspaper stands and filled with tacky advertisements for more or less well-documented ways of getting "big muscles in ten weeks", journals about aesthetic surgery are definitely "scientific", they are published by respectable academic publishers and are only available to the elect in medical libraries. It is possible to find articles and adverts about aesthetic surgery in more popular literature, but such material is invariably targeted at the consumer and not at the practitioner of the "art".

\section{The body artist and the work of art}

Both of the practices we are considering here can be illuminated in an interesting way by looking at two core concepts in aesthetics, ie "the artist" and "the work of art".

Today a "body artist" may be a tattooist, someone performing piercing, branding or scarification, or a "real" artist using his or her own body as the medium of artistic expression. However, it seems quite natural to ask whether aesthetic surgeons and bodybuilders should not also be viewed as "body artists" in the literal sense of these words. They work on the body with the aim of changing it to produce an aesthetic experience in other people.

If we look at the aesthetic surgeons first we see that their artistic work is constrained in various ways. The material on which they work is very delicate and difficult to work with, and due to the variable results of interventions in a biological organism (caused by differential rates of healing and other factors) the final effects of a given intervention cannot be predicted with certainty. This is similar to problems encountered by other artists working with fragile materials. A greater problem for the analysis of the surgeons as artists is, however, that there are social and ethical constraints on the possible range of modifications the artist can make to the material. The artist is thus not free to do whatever he or she wants or likes to do. The artistic intervention has, for ethical reasons, to be agreed upon with the material (ie the patient) beforehand, and the possible changes made to the material have to fall within certain socially constrained limits. This last constraint would pose no problem if the margins for the allowable changes were wide, or if they were at least widely variable from patient to patient. In that case there would still be a possibility for the artist to play a major creative role. This is, however, not the case. The margins for the creativity of the aesthetic surgeon are very small, both seen with regard to individual patients, and with regard to the surgeon's total production (note that the kind of creativity we are talking about is artistic creativity not technical creativity in the sense of inventing new surgical techniques to treat difficult cases). It is, for instance, not the case that there is a wide variability in the desires of different patients. These limits on the surgeon's creativity are very nicely brought out in a small piece by Woody Allen, describing a correspondence between the dentist van Gogh and his brother Theo. In this correspondence we are asked to imagine a really artistic dentist whose main interest in dental work is artistic expression. The first letter begins:

\section{"Dear Theo}

"Will life never treat me decently? I am wracked by despair! My head is pounding. Mrs Sol Schwimmer is suing me because I made her bridge as I felt it and not to fit her ridiculous mouth. That's right! I can't work to order like a common tradesman. I decided her bridge should be enormous and billowing with wild, explosive teeth flaring up in every direction like fire! Now she is upset because it won't fit in her mouth! She is so bourgeois and stupid, I want to smash her. I tried forcing the false plate in but it sticks out like a star burst chandelier. Still, I find it beautiful. She claims that she can't chew! What do I care whether she can chew or not!"

Such a dentist, or a similar aesthetic surgeon is obviously impossible to imagine working in real life. The idea that an aesthetic surgeon could create something radically new is perhaps not conceptually impossible, but is at the very least, difficult to reconcile with his or her role within the medical profession. The aesthetic surgeon is constrained by functional considerations but also by social values and views on beauty and proper appearance. In American aesthetic surgery it has, for instance, been characteristic that the nose aimed at in the ever popular "nose job" has changed over time in synchrony with societal definitions of "a beautiful nose".

Within bodybuilding the artist/athlete is also constrained by the limitations of the human body and constrained by the rules which the judges at bodybuilding competitions apply when they judge different performances. This does not, however, prevent the really big stars in the game from being innovative. They can invent new ways of developing certain muscle groups which makes them look more prominent or more defined, or they can develop new poses which display the body in new and interesting ways. The bodybuilders also have 
the advantage as artists in that the material they are working with is themselves. The ethical constraints are therefore more flexible. It is true that bodybuilders work towards a very stereotypic ideal image but, especially for female bodybuilders, this ideal image is far removed from the general ideal female body image in society (see for instance the section about the use of female bodybuilders in advertisements in Ffrench). ${ }^{6}$

\section{The function of aesthetic surgery}

"Sculpture is not a science but a very mechanical art, because it causes its executant to sweat and bodily fatigue. A sculptor only need know the simple measurements of the limbs and the nature of movement and postures. With this knowledge he can complete his works, demonstrating to the eye whatever it is, and not inherently giving any other cause for admiration in the spectator, unlike painting, which on a flat surface uses the power of its science to display the greatest landscapes with their distant horizons."

In classical aesthetics there are important discussions about the function of art and the distinction between art objects and other objects. Here I want initially to draw on some ideas developed by the British critic, John Ruskin. ${ }^{8}$ Ruskin makes a distinction between simple illusion and imitation, where objects exhibiting simple illusions are objects aimed at making the viewer believe that something else is the case than is really the case, whereas the true art objects are the objects exhibiting imitation. ${ }^{9}$ In imitation the viewers are not fooled, but exactly because they are not fooled they can see the skill the artist has put into making the work. The reason that Ruskin sees imitation as the true hallmark of art is that noticing skilful imitation gives us distinct aesthetic pleasure. Ruskin does not try to explain where this pleasure derives from, but simply claims it to be there and appeals to our everyday aesthetic experiences to confirm this.

If we look at aesthetic surgery it is characterised by aiming primarily at simple illusion. The enlarged breasts are normally intended to look like natural large breasts, and not like enlarged breasts. The corrected roman nose should not show any scars but should be indistinguishable from a naturally shaped acceptable nose. Thus, according to Ruskin, aesthetic surgery would only be a very deficient form of art, since it could almost by definition never aim to go beyond simple illusion.

Aesthetic surgery is also interesting as a possible art form in that it has no-and desires no- audience. If anybody (except the patient and perhaps his or her partner) consciously notices the work of the surgeon it entails that there is a defect in the work. Thus if the patient is a work of art, it is a very anomalous work of art which is made to be seen (ie the changes made are made exactly to change visual appearance), ${ }^{10}$ but at the same time made not to be seen (ie noticed). The artist/ surgeon is also usually not expected or allowed to declare him- or herself as author of a particular work. Aesthetic surgeons who too often and against the wishes of their works of art declared themselves to be authors: "I produced those breasts", "His nose would still be crooked if it were not for me", or "See this innovative placement of the cut for the face-lift", would soon be in great trouble.

We could account for such a strange work of art within an aesthetic of sense where the only thing that mattered was the immediate aesthetic experience obtained when viewing the work of art, and where no further attempts where made to distinguish further between different classes of aesthetic objects or experiences. This would, however, amount to collapsing any distinction between art objects, and everyday objects with some kind of aesthetic dimension (including natural objects)

In contrast the art of the bodybuilder is explicitly produced to be exhibited, seen, and admired. The co-existence of the work of art and the artist coupled with the very public and directly competitive nature of bodybuilding competitions is perhaps part of what makes us slightly sceptical towards bodybuilding as a sport.

\section{The ready-made body}

"We thus see (1) that genius is a talent for producing that for which no definite rule can be given; it is not a mere aptitude for what can be learned by rule. Hence originality must be its first property." "11

Human beings have deliberately changed their appearance as long back as we have any reliable knowledge about our species. Permanent bodychanging techniques such as tattooing and various methods to mould bones in children are known in all cultures. Historically these techniques have been used in a strictly traditional way in the sense that a given group has a specific limited repertoire of bodily changes which is either applied to all members of the group, or to sub-groups according to status in society.

In our modern societies body-changing techniques are not promoted and used in the same overtly traditional and ritualistic way. We do not 
normally go to the tattoo artist to be made more similar or to get a socially recognised sign of a specific status, but in order to underscore our individuality (even though the first tattoo may still be an important rite of passage).$^{12}$ The fact that all the other persons getting very similar changes made also do it to underscore their individuality does normally escape our attention, and we are therefore spared the realisation of the selfdefeating nature of this particular form of pursuit of individuality.

In this context it becomes interesting to know what kind of art objects aesthetic surgeons produce. Do they produce unique works of art, series of almost identical works (like a series of prints) or something else? Initially this question may seem absurd, since aesthetic surgeons work on human beings who are both before and after the surgery unique as persons both in a bodily and a psychological sense. It is, however, possible to argue that what aesthetic surgeons do is much more like producing a series of identical prints, or perhaps more surprising, closer to framing a "duchampian ready-made", than producing unique pieces of art. Duchamps's innovative move was to take already existing objects ("readymades") and transform them into art by framing them, giving them a title, and displaying them as art. What the aesthetic surgeon does is in many ways analogous to this model of artistic expression.

As we have discussed above, the aesthetic surgeon's latitude for "artistic expression" is severely limited. The aim is mainly to reproduce in the patient's body some socially acceptable or desirable stereotype of the body part in question. The surgeon who can thus reproduce a number of identical acceptable noses, breasts or hips is highly likely to be a very successful artist/surgeon.

What has this to do with a ready-made like, for instance, Duchamps's snow shovel? The shovel was a finished product before Duchamps laid his hands on it and transformed it into an art object by framing it and giving it a title, but the patient is physically changed by the surgeon. This is obviously true, but there are nevertheless strong affinities between readymades and the (intended) results of the surgeon's efforts. If it were technically feasible, a possible goal of aesthetic plastic surgery would be not only to change one facial part, but to change the face to fit a certain predefined ideal. In this sense the remaining body would simply be a frame for a readymade face, taken from the shelves of the surgeon's stockroom. Now, this is obviously not feasible today, and may never be, but it is nevertheless a natural extension of some already present tendencies in aesthetic surgery.
This allegiance to a ready-made model has as a negative side effect, that it creates a further bodily hegemony of the already hegemonic privileged social groups. The beautiful body to be emulated, striven for, and ultimately bought is the body of the societal ideal ${ }^{13}$ (this raises obvious ethical problems, see for instance Little. ${ }^{14}$ )

\section{The incentive to buy}

Since the disappearance of the prince, bishop or rich merchant who, as a patron, could secure the livelihood of an artist it has been a general phenomenon that art is bought and sold, and that the artist lives on what he or she can sell (living mainly on media appearances is a new thing in the history of art). Aesthetic surgery is also bought and sold, but again in an anomalous form compared to other works of art. When persons buy a work of art, it can be for a variety of reasons. They may simply like the piece, they may want to show off, they may want to invest etc. In some of these cases the work of art is bought for its own sake, and in others it is bought as a means to reach certain goals. The cases do, however, have the common characteristic that it is the work of art which is bought in itself.

In aesthetic surgery it is not the work of art which is bought in itself (since the patient already owns the material used for the production) but the artist's time and the use of his or her equipment and facilities. This could be seen as analogous to the situation in the performing arts, where we pay musicians and ballet dancers for their performance and not for any specific product (except in the case of recorded performances). This analogy is, however, problematic on closer scrutiny. For the analogy to hold it would have to be the case that we paid aesthetic surgeons primarily in order to watch, listen to, or feel them work. Most of those who pay for aesthetic surgery (ie patients) would probably not have the slightest desire to experience the surgery being performed, and might even complain if they had such experiences. A further problem with the analogy is that although I do not buy the work of art in the normal sense when I buy aesthetic surgery, I do expect to take something tangible with me from the clinic.

The incentive to buy is also somewhat anomalous. Aesthetic surgery is often bought in order to conform better to a fairly restrictive ideal of physical beauty. This may have other positive effects in the long run. We have a number of studies that show that physical beauty brings with it rewards in the form of societal recognition, higher self esteem, and other positive effects. ${ }^{15}{ }^{16}$ This could be seen as analogous to the attempt to buy social 
respectability through the purchase of a major work of art. This analogy is, however, not without problems. We furthermore know that some customers for aesthetic plastic surgery buy this kind of surgery not because they are unsatisfied with their appearance as such, but because they want to be able to blend better into social life by removing some ethnic characteristic. ${ }^{17} 18$ This incentive for buying seems to have no analogues when compared to reasons for buying "normal" works of art

The art of the bodybuilder is bought and sold in the market-place. The best bodybuilders are professionals who earn their living by displaying their "artwork". Now, we may suspect that they also gain some pleasure themselves by contemplating their body, hence the large number of mirrors in bodybuilding studios. This does not, however, detract much from the fact that even on this score bodybuilding approaches art more nearly than aesthetic surgery does.

\section{Art, craft or trade - final considerations}

Somewhat surprisingly the analysis above tends to show that bodybuilding is closer to being an art form on traditional criteria, than is aesthetic plastic surgery. Bodybuilders are closer to being artists, their artworks are closer to being artworks, and their relationship with their audience is closer to the traditional relationship between artist, work of art and audience.

It is quite evident that the aesthetic plastic surgeon aims to produce a change in the body of the patient which is aesthetically pleasing to the patient and to his or her environment, but this is in a more trivial sense of aesthetics than the one we usually associate with art. The aesthetic surgeon is thus no artist, but "merely" an expert craftsman producing a series of ready-mades which conform to conventional criteria for beauty.

This may have implications both for the ethical assessment of this kind of surgery, and for the analysis of other medical and surgical treatments that are directly aimed at changing the appearance of patients/clients. If the main aim of these forms of activity is the reproduction of conventional norms of appearance, as has been argued here for aesthetic surgery, it becomes more difficult to argue that they express the genuine and authentic aesthetic choices of either the patient/client or the surgeon. One possible defence of these practices is thereby weakened. This paper has mainly focused on the role of the surgeon, but a similar analysis could probably be given of the role of the patient/ client/buyer. Such an analysis would have to look at whether the patient is primarily interested in buying a unique work of art, or whether he or she is perhaps more interested in a slight variation of a common and banal theme.

\section{Acknowledgements}

This paper was written as a part of the project entitled "Beauty and the Doctor", sponsored by the European Union BIOMED II research programme and co-ordinated by the Centre for Medical Ethics, Erasmus University, Rotterdam. The author thanks the European Commission, DG XII, and the other participants in the project for stimulus and support. All views expressed in the paper are solely the views of the author.

Søren Holm is Reader in Bioethics at the Centre for Social Ethics and Policy, University of Manchester and Professor at the Centre for Medical Ethics, University of Oslo, Norway

\section{References and notes}

1 Aquinas T. Summa theologica [q 39, art 8]. Quoted in: Townsend D, ed. Aesthetics - classic readings from the western tradition. Sudbury, MA: Jones and Bartlett Publishers, 1996: 105.

2 Hinderer UT. Aesthetic surgery: private clinics-problem or solution. In: de Beaufort I, Hilhorst M, Holm S, eds. In the eye of the beholder-ethics and medical change of appearance. Oslo: Scandinavian University Press, 1996: 84-96.

3 It is important to note that aesthetic plastic surgery in Europe and in the USA are two very different things. Whereas most pretence of being a medical specialty doing restorative work has pretence of being a medical specialty doing restorative work has been given up in the US, many European plastic surgeons would still claim their goal to be congruent with the general medical goal of restoring but not enhancing normal function. See: Haiken E. Venus envy-a history of cosmetic surgery.

Baltimore: The Johns Hopkins University Press, 1997.

4 The aesthetics discussed and deployed in analyses in this paper is classical philosophical aesthetics, ie aesthetics as it was thought and taught before post-modernism allegedly dissolved the whole tradition of aesthetics in a stream of "intertextuality" and "free play". The reason for looking through the lens of classical aesthetics is primarily that in postmodern aesthetics all normative aesthetic content seems to have been lost. All classic categories are dissolved, and it becomes impossible even to begin to give an answer to whether something is, for instance "a work of art". See: Hanfling O, ed. Philosophical aesthetics - an introduction. Oxford: Blackwell Publishers, 1992.

5 Allen W. If the impressionists had been dentists. Quoted in Dey I. Qualitative data analysis-a user-friendly guide for social scientists. London: Routledge, 1993: 269 .

6 Ffrench G. The not so hidden persuaders: images of the nude in advertising. In: de Beaufort I, Hilhorst $\mathrm{M}$, Holm S, eds. In the eye of the beholder-ethics and medical change of appearance. the eye of the beholder-ethics and medical change of

7 da Vinci L. On painting. Quoted in: Townsend D, ed. Aesthetics -classic readings from the western tradition. Sudbury, MA: Jones and Bartlett Publishers, 1996: 106

8 Ruskin J. Modern painters [5 vols]. London: G Allen, 1897

9 The application of Ruskin's ideas would be problematic if we were discussing a modern non-figurative form of art, but both aesthetic surgery and bodybuilding are distinctly figurative. The goals of these two activities are pursued within a distinctly naturalistic framework, and this is partly what makes the idea of an impressionist bodybuilder or an aesthetic surgeon so strange.

10 A few operations do not have this characteristic (for example penile enlargement operations) but the great majority do.

11 Kant I. Critique of judgment. Quoted in: Townsend D, ed. Aesthetics - classic readings from the western tradition. Sudbury, MA: Jones and Bartlett Publishers, 1996: 178.

12 In this context it is, however, interesting to note how ancient ritual tattoos (Maori, Nordic etc) have become popular as a "clean" form of modern tattooing.

13 Bartley S. Femininity $\mathcal{E}$ domination: studies in the phenomenology of oppression. New York: Routledge, 1990. 
48 Changes to bodily appearance: the aesthetics of deliberate intervention

14 Little MO. Suspect norms of appearance and the ethics of complicity. In: de Beaufort I, Hilhorst M, Holm S, eds. In the eye of the beholder - ethics and medical change of appearance. Oslo: Scandinavian University Press, 199: 151-67.

15 Berscheid E, Gangestead S. The social psychological implications of facial physical attractiveness. Clinics in Plastic Surgery 1982;9:289-96.

16 Eagly AH, Ashmore RD, Makhijani MG, Longo LC. What is beautiful is good, but: a meta-analytic review of research on the physical attractiveness stereotype. Psychological Bulletin 1991; 110:109-28.

17 Jacobson WE, Meyer E, Edgerton MT, Canter A, Slaughter R. Screening of rhinoplasty patients from the psychological point of view. Plastic Reconstructive Surgery 1961;28:279-81.

18 Meyer E, Jacobson WE, Edgerton MT, Canter A. Motivational patterns in patients seeking elective plastic surgery (women who seek rhinoplasty). Psychosomatic Medicine 1960;22:193203. 